\title{
Evaluation of Anti-arthritic Activity of Hydroalcoholic Extract of Capparis decidua (Forssk.) Edgew. on Freund's Complete Adjuvant-induced Arthritis in Rats
}

\author{
Prashant Kumar Dhakad ${ }^{1, *}$, Pramod Kumar Sharma ${ }^{1}$, Sokindra Kumar ${ }^{2}$ \\ ${ }^{1}$ Department of Pharmacy, Galgotias University, India \\ ${ }^{2}$ R.V. Northland Institute (RVNI), India
}

Copyright $\bigcirc 2018$ by authors, all rights reserved. Authors agree that this article remains permanently open access under the terms of the Creative Commons Attribution License 4.0 International License

\begin{abstract}
Capparis decidua has been traditionally used in the Ayurveda to treat rheumatoid arthritis and it is reported to have anti-inflammatory and analgesic activity. Considering its anti-inflammatory activity the present research work has been designed to assess the anti-arthritic activity in Wistar rats. The anti-arthritic activity of hydroalcoholic extract of $C$. decidua root, stem and leaves was evaluated using Freund's complete adjuvants (FCA) induced arthritic models in Wistar rats. Oral administration of $C$. decidua extract at the dose of $100 \mathrm{mg} / \mathrm{kg}, 200 \mathrm{mg} / \mathrm{kg}$, per se group (only $200 \mathrm{mg} / \mathrm{kg}$ of $C$. decidua) was subjected to Wistar rats for 28 days. Standard drug Diclofenac sodium at the dose of $5 \mathrm{mg} / \mathrm{kg}$ and FCA at $1 \mathrm{mg} / \mathrm{ml}$ was used in the study. The normal control group was administered only distilled water at $1 \mathrm{ml} / \mathrm{kg}$ without induction of arthritis. The arthritic investigation was carried out on basis of parameters including changes in body weight, paw volume, hematological studies like ESR count, RBC count, WBC count, Hemoglobin count, platelet count. At the end of study period, animals were sacrificed and histological parameters were evaluated. Phytochemical analysis of $C$. decidua extract was done to assess the various constituents present in $C$. decidua. The results of $C$. decidua extract administration significantly $(\mathrm{P}<0.001)$ attenuated the body weight, paw volume, hematological alteration induced by the FCA in dose-dependent manner. The tarsal joint was extracted for histopathological studies. The overall results indicate that $C$. decidua extract $(100 \mathrm{mg} / \mathrm{kg}$ and $200 \mathrm{mg} / \mathrm{kg}$ ) showed a potent protective effect against FCA induced arthritic rats which could be attributed to phytoconstituents present in C. decidua and its effect is comparable to the standard drug diclofenac sodium.
\end{abstract}

Keywords Capparis decidua, Hydroalcoholic Extract, Freund's Complete Adjuvant, Rheumatoid Arthritis

\section{Introduction}

Joint inflammation and related issue, including rheumatoid arthritis (RA), are normal illnesses influencing a great many individuals. RA is characterized by articular wounds having an inflammatory propagation of synovial cells, achieving an almost entire functional defect. It influences around $1 \%$ of the all-inclusive community. RA is a kind of chronic inflammatory immune system infection. In spite of the fact that a number of medications utilized as a part of the treatment of RA have been developed over the previous couple of decades, there is as yet a requirement for more effective drugs with lower side effects [1]. This autoimmune disorder is characterized by pain, synovial membrane inflammation and confined joint development because of tissue harms. In RA, bone disfigurements and inability of joint capacity occurs due to dynamic disintegration of articular ligament in synovial joint via generation and invasion of auto-antibodies in it. The main pathological changes of RA incorporate hyperplasia of synovial membrane, penetration of fiery cell, and neovascularization, which eventually prompt ligament disintegration and articular destruction. Degradation of cartilage is a more mind-boggling occasion including the local arrival of proinflammatory substance, for example, prostaglandins, leukotrienes, elastase, and proteases including metalloproteases and lysosomal compounds that intervene aggravation in joints and in the synovial liquid in RA[2]. Women are three times more prone to get RA than men. The fundamental classes of medications used to treat rheumatoid joint inflammation are analgesics, disease-modifying antirheumatic drugs (DMARDs), non-steroidal anti-inflammatory drugs (NSAIDs), corticosteroids and immunosuppressive drugs. In any case, these medications deliver some undesirable symptoms, for example gastrointestinal ulcergenicity and renal morbidity. Thus, these days restorative herb in the treatment and counteractive action of illnesses is drawing attention by 
researchers around the world [3]. Capparis decidua Edgew., belonging to the family Capparidaceae, is a glabrous, highly branched, spiny, spiked, relatively leafless bush or little tree developing fiercely in dry, open badlands all through the parched and semi-dry zones of India and diverse parts of the world. It is commonly called as Kair, or Karil [4]. Ripened fruits of this plant has sharp hot taste; astringent to the entrails, decimates foul breath, biliousness and urinary purulent releases; it is useful in cardiovascular inconveniences. This plant is being utilized as a laxative, emmenagogue, alexipharmic, and aphrodisiac. It improves appetite and is good for rheumatism, cough, lumbago, hiccough, and asthma [5]. Capparis decidua (Forssk.) Edgew. contains constituents like flavanoids, phenolic compounds, steroids, alkaloids, vitamins, quarternary ammonium compounds, terpenoids and many more phytoconstituents that are responsible for its medicinal value [6]. Enough phytochemical work has been done so far on $C$. decidua, which has been reported to contain indoles, $\beta$-sitosterols, oxygenated heterocyclic compounds, aliphatic constituents, isocodonocarpine, tannins, diterpene alcohol, $\beta$-carotene, and sufficient quantities of alkaloids [7]. The stem bark of $C$. decidua showed the presence of n-triacontanol, n-pentacosane, and $\beta$-sitosterol, 1-stachydrine. Root bark contains Capparis diterpene, Capparideciduasterol, capparisterol, capparisditerpenyl ester. Previous studies conducted on various parts of this plant showed numerous pharmacological activities like antibacterial, antifungal, antiparasital [8-9], antimicrobial, anti-inflammatory [10], antioxidant, antiplaque [11-12], anthelmintic [13], antidiabetic [14], hepatoprotective [15], antisebum [16], antisclerotic [17], antihyperlipidemic [18], anti termite [19], analgesic, sedative, and anticonvulsant [20].

\section{Material and Methods}

\subsection{Procurement and Authentication of Plant Material}

The complete plant of Capparis decidua was collected fresh from Jaipur, Rajasthan, India. The plant was taxonomically identified and authenticated by Prof. Kailash Agrawal, Convener Herbarium committee, Department of Botany, University of Rajasthan, Jaipur. A voucher specimen was deposited at the herbarium of the Department of Botany, University of Rajasthan, Jaipur, Rajasthan, India (R. No.-RUBL 211645).

\subsection{Preparation of Plant Extract}

C.decidua root, stem and leaves were washed with tap water followed by distilled water and then cut and dried under the shade. The dried plant parts were comminuted into moderately coarse powder and passed through sieve no. 40 , stored in a tightly closed container. The dried and powdered plant material was Soxhlet extracted with water and ethyl alcohol (99.9\%) in the ratio of 30:70. The extraction was carried out for $24 \mathrm{~h}$ at room temperature with mild shaking. The extract was filtered and concentrated at $48^{\circ} \mathrm{C}$ by keeping on a water bath and weight of residue was recorded. The percentage yield of hydroalcoholic extract was found to be $42.8 \%$. The collected extract was stored in a sterile container for further use.

\subsection{Drugs and Chemicals}

Freund's complete adjuvant (FCA) was obtained from Sigma-Aldrich Ltd. (USA). Diclofenac sodium was procured as gift sample from Afton Pharma, Gujarat, India. All other chemicals and reagents used for study were of analytical grade procured from approved organization.

\subsection{Acute Toxicity Studies}

The acute toxicity of the extract was studied in adult male Wistar rats. They were divided into five groups each consisting of five rats. The suspension of the extract was administered orally at four different doses of 500, 1000, 2000 and $4000 \mathrm{mg} / \mathrm{kg}$, respectively, to different groups of rats separately. Control animals received $10 \mathrm{ml} / \mathrm{kg}$ of distilled water orally. The animals were observed continuously for the initial $4 \mathrm{~h}$ for behavioral changes and mortality and intermittently for the next $6 \mathrm{~h}$ and then again at $24 \mathrm{~h}$ and $48 \mathrm{~h}$ after dosing. The behavior parameters observed were convulsion, hyperactivity, sedation, grooming, loss of righting reflex and increased respiration.

\subsection{Animals}

Female Wistar rats of body weight 150-200g were used for the study. The animals were maintained under standard environmental conditions and were fed with standard pellet diet and water ad libitum. The study was approved by Institutional Animal Ethics Committee (Registration No.-1149/PO/ERe/07/CPCSEA). CPCSEA guidelines were adhered to during the maintenance and experiment.

\subsection{Freund's Complete Adjuvant-Induced Arthritis}

Arthritis was be induced to all the groups of animals except normal control group by single intra-dermal injection of $0.1 \mathrm{~mL}$ of Freund's Complete Adjuvant (FCA) containing $1 \mathrm{mg} . \mathrm{mL}^{-1}$ Mycobacterium tuberculosis H37Ra suspension in sterile paraffin oil into a foot pad of the left hind paw of female rats. The rats were anesthetized with ether inhalation prior to and during adjuvant injection, as the very viscous nature of the adjuvant exerts difficulty while injecting.

Treatment with hydroalcoholic extract of $C$. decidua, Diclofenac sodium and normal control (Distilled water) 
was started on the 14th day after arthritis induction and continued for 28 days. The paw volume of all the animal groups was measured by plethysmograph at 1, 4, 10, 14, 17, 21, 24 and 28 after the injection of Freund's complete adjuvant. [21]

The animals were divided into six groups consisting of six animals per group

Group I: Normal control group (distilled water $1 \mathrm{ml} / \mathrm{Kg}$ p.o) (non-arthritic), $(\mathrm{n}=6)$

Group II: FCA injected arthritic control; $(\mathrm{n}=6)$

Group III: Arthritic animals treated with Diclofenac Sodium $(5 \mathrm{mg} / \mathrm{kg} /$ day $),(\mathrm{n}=6)$

Group IV: Arthritic animals treated with hydroalcoholic extracts of C. decidua (100 $\mathrm{mg} / \mathrm{kg}$ body weight/day p.o), $(\mathrm{n}=6)$

Group V: Arthritic animals treated with hydroalcoholic extracts of $C$. decidua $(200 \mathrm{mg} / \mathrm{kg}$ body weight/day p.o), $(\mathrm{n}=6)$

Group VI: Per se group (normal group where only plant extract with $200 \mathrm{mg} / \mathrm{kg}$ will be administered p.o)

Anti-arthritic effect of hydroalcoholic extract of $C$. decidua was evaluated on body weights changes and paw volume on day $1,4,10,14,17,21,24$ and day 28 . On day 28 the animals were anesthetized with ether and the blood was withdrawn by tail vein for the estimation of various hematological parameters followed by histopathological analysis of ankle joint of rats.

Measurement of Bodyweight - Body weight was recorded on day 0 just before FCA injections and thereafter on day $1,4,8,12,16,20,24$, and day 28. [22]

Measurement of paw volume - Paw volume was measured using a Plethysmometer (UGOBasile, Italy) on day 0 before FCA injections and thereafter on day1, 4, 8 , $12,16,20,24$, and day 28 [19]. The change in paw volume was calculated as the difference between the final and initial paw volume. [23]

Haematological parameters - On day 28, haematological parameters like red blood cell (RBC) count, white blood cell (WBC) count, haemoglobin (Hb), and platelets (PLT) were determined by usual standardized laboratory method. [24]

Histopathological analysis of ankle joints - On day 28, ankle joints were separated from the hind paw and immersed in $10 \%$ buffered formalin for $24 \mathrm{~h}$ followed by decalcification in $5 \%$ formic acid, processed for paraffin embedding sectioned at $5 \mu$ thickness. The sections were stained with haematoxylin-eosin and evaluated under light microscope with 10 times magnifications for the presence of inflammatory cells, hyperplasia of synovium, pannus formation and destruction of joint space [25].

\subsection{Statistical Analysis}

The data were represented as a mean \pm standard error of the mean (SEM). Statistical significance was carried out employing one-way analysis of variance (ANOVA) followed by Dunnett's Multiple Comparison Test where $\mathrm{P}<0.05$ was considered statistically significant using Graph Pad Prism version 5.03 software.

\section{Results}

The oral administration of hydroalcoholic extract of $C$. decidua did not provoke any gross behavioral changes or manifestations of toxic symptoms such as increased or decreased motor activity, loss of right reflex, ataxia, clonic convulsions, muscle relaxation spasticity, tremors, tonic extensions, lacrimation, salivation, weight loss, watery diarrhea, writhing and urination over a period of $48 \mathrm{~h}$. The hydroalcoholic extract of $C$. decidua was found to be non-lethal even at the maximum single dose of $4.0 \mathrm{~g} / \mathrm{kg}$. The dose of hydroalcoholic extract of $C$. decidua was selected on this basis and as per the earlier studies conducted by Goyal et al 2009 [7] where $100 \mathrm{mg} / \mathrm{kg}$ and $200 \mathrm{mg} / \mathrm{kg}$ of $C$. decidua showed significant results $(\mathrm{P}<0.05)$ without any toxic effects at these doses.

The rats in the FCA treated group lost body weight as compared with the $C$. decidua extract treated and diclofenac treated groups. The body weight of $C$. decidua at $100 \mathrm{mg} / \mathrm{kg}, 200 \mathrm{mg} / \mathrm{kg}$ and per se significantly $(\mathrm{P}<0.001)$ increased from day 17 th onwards till day 28 th as compared to FCA treated group rats. While Diclofenac treated groups also showed the significant result $(\mathrm{P}<0.001)$ from day 17 th onwards till day 28th as compared to FCA treated group rats. The effect produced by $C$. decidua extract at 100 $\mathrm{mg} / \mathrm{kg}$ and $200 \mathrm{mg} / \mathrm{kg}$ produced a similar result as seen in a diclofenac-treated group on days 17, 21, 24 and 28. (Figure 1)

There was significant $(\mathrm{P}<0.001)$ increase in paw volume of all the rats treated with FCA compared to control groups' rats. Hydroalcoholic extract of $C$. decidua $(100$ and $200 \mathrm{mg} / \mathrm{kg})$ significantly $(\mathrm{P}<0.001)$ lowered the paw volume from day 14 onwards as compared to FCA control group. Per se group also showed significant $(\mathrm{P}<0.001)$ reduction in paw volume from day 4 onwards till $28^{\text {th }}$ day. C. decidua extract at $100 \mathrm{mg} / \mathrm{kg}$ was less effective initially $(\mathrm{P}<0.05)$ till $14^{\text {th }}$ day but thereafter showed more significant result $(\mathrm{P}<0.001)$. Diclofenac $5 \mathrm{mg} / \mathrm{kg}$ showed significant $(\mathrm{P}<0.001)$ reduction in paw volume from day 4 onwards. (Figure 2)

The significant increase in levels of platelets $(\mathrm{P}<0.001)$, ESR count $(\mathrm{P}<0.001)$ and WBC $(\mathrm{P}<0.001)$ and significant decrease in levels of RBC $(\mathrm{P}<0.001)$ and $\mathrm{Hb}(\mathrm{P}$ $<0.001)$ were observed in FCA group as compared to normal control group indicating a stimulation of immune response towards FCA in arthritic rats. Treatment with hydroalcoholic extract of C. decidua $(100 \& 200 \mathrm{mg} / \mathrm{kg})$, per se group significantly $(\mathrm{P}<0.001)$ inhibited the stimulation of immune response towards FCA by decreasing blood WBC, ESR, and increasing $\mathrm{Hb}$ and RBC compared to FCA treated group. Diclofenac sodium treated 
rats also showed significant result $(\mathrm{P}<0.001)$ by reducing the WBC, ESR count and platelet and increasing hemoglobin and RBC levels. (Figure 3-7)

As shown in Figure 4, the histopathological evaluation of the ankle joint in FCA treated group exhibited dense neutrophil cell infiltration causing edematous synovium, destructive lesions in articular cartilage, vascularity formation into the joint space, synovial hyperplasia, pannus formation and cartilage erosion. Treatment with extract of $C$. decidua reduced infiltration of inflammatory cells, joint space narrowing, pannus formation, synovial hyperplasia and cartilage erosion in a dose-dependent manner as evidenced from the histopathology sections of $C$. decidua treated rats. (Figure 8.1-8.6)

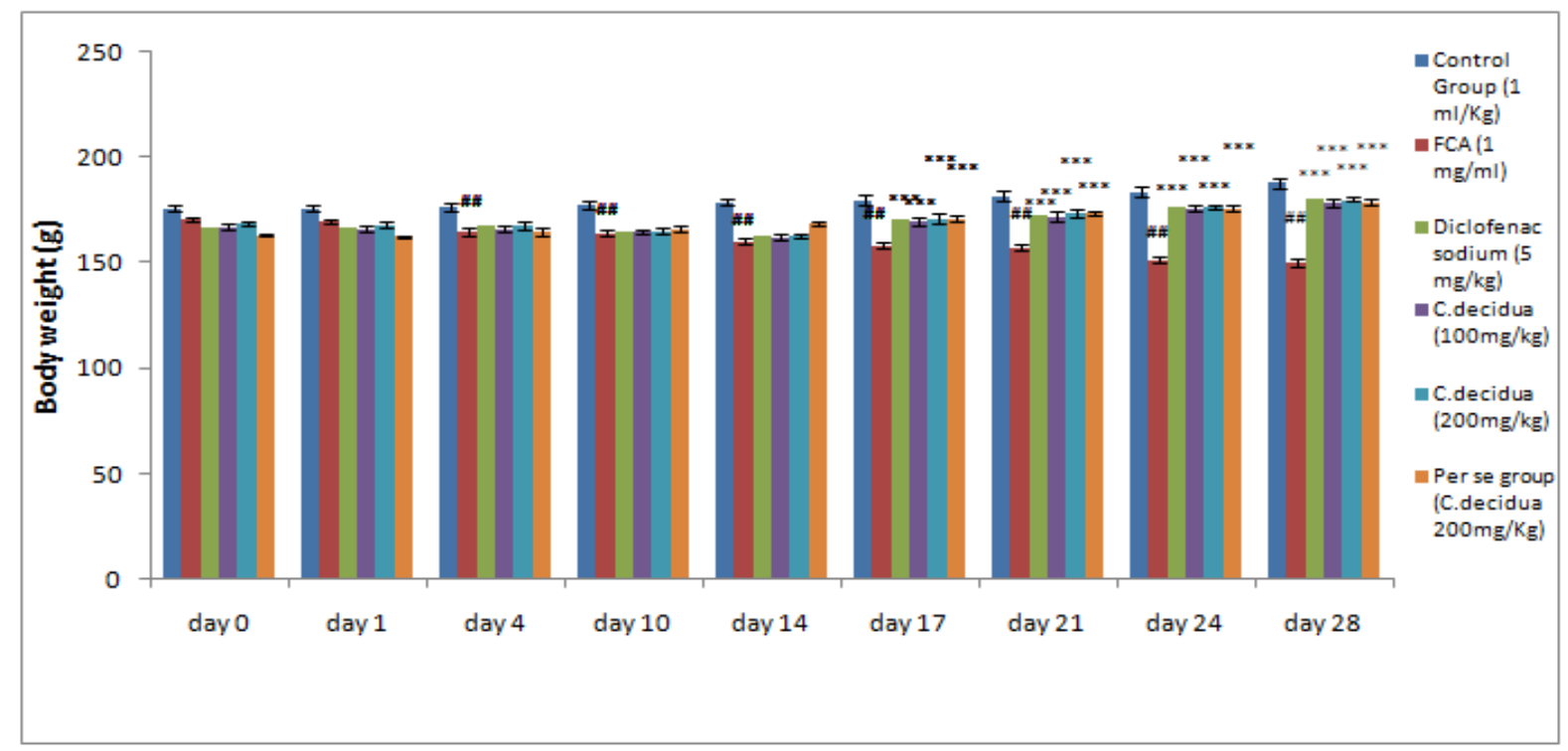

Figure 1. Effect of Capparis decidua on body weight ( $\mathrm{g}$ ) in FCA-induced arthritic rats; Data are expressed as mean \pm S.E.M. $(n=6)$. Data analyzed by one-way Analysis of Variance (ANOVA) followed by Dunnet's multiple comparison tests. ${ }^{\#} \mathrm{P}<0.001$ as compared to control. ${ }^{* * *} \mathrm{P}<0.001$ as compared to FCA treated

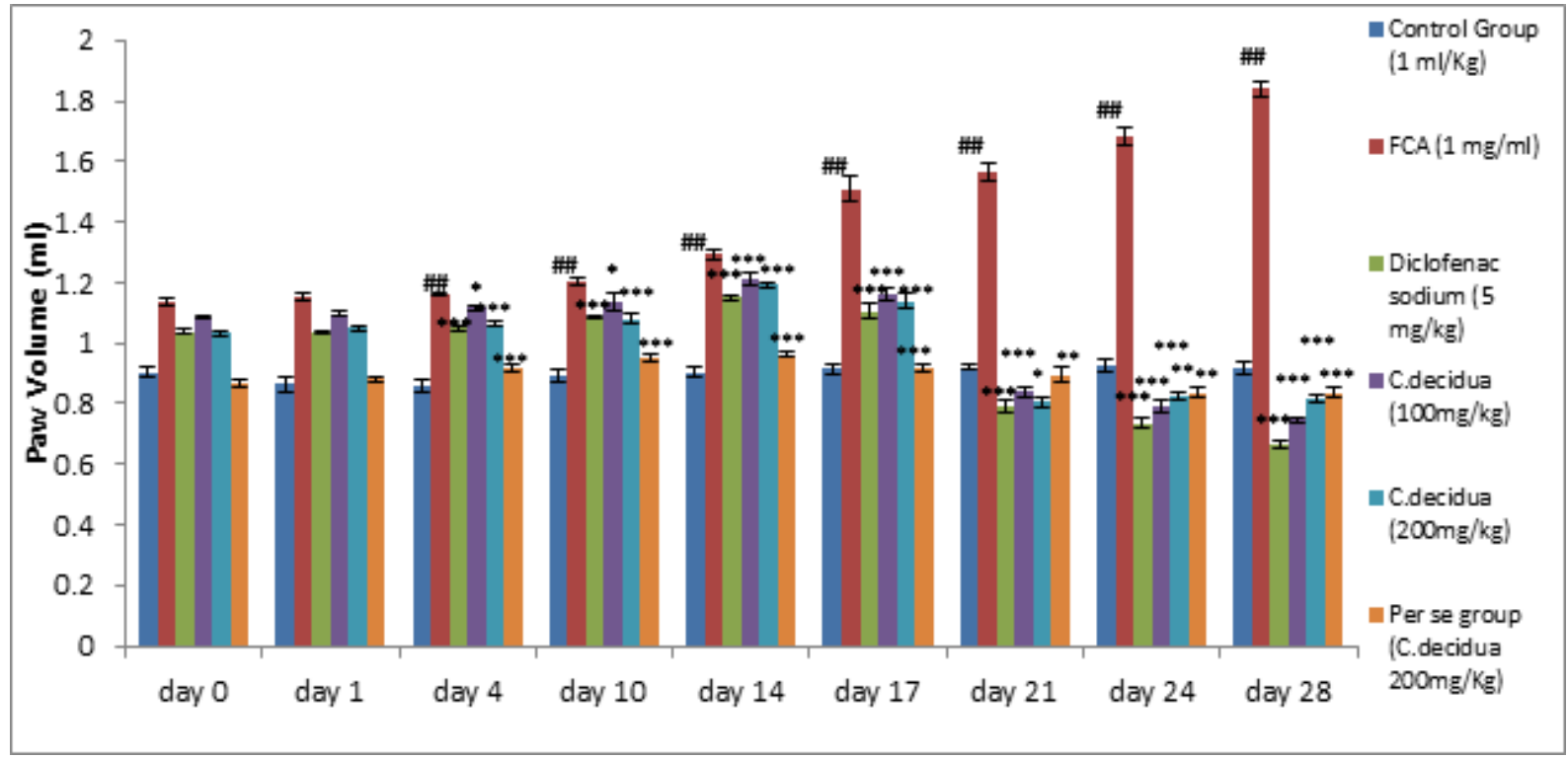

Figure 2. Effect of Capparis decidua on Paw volume test in FCA-induced arthritic rats; Data are expressed as mean \pm S.E.M. ( $n=6)$. Data analyzedby one-way Analysis of Variance (ANOVA) followed by Dunnet's multiple tests for comparison. ${ }^{\# \#} \mathrm{P}<0.001$ as compared to control. ***P $<0.001$ as compared to FCA. ${ }^{*} \mathrm{P}<0.01$ as compared to FCA. ${ }^{*} \mathrm{P}<0.05$ as compared to FCA. 


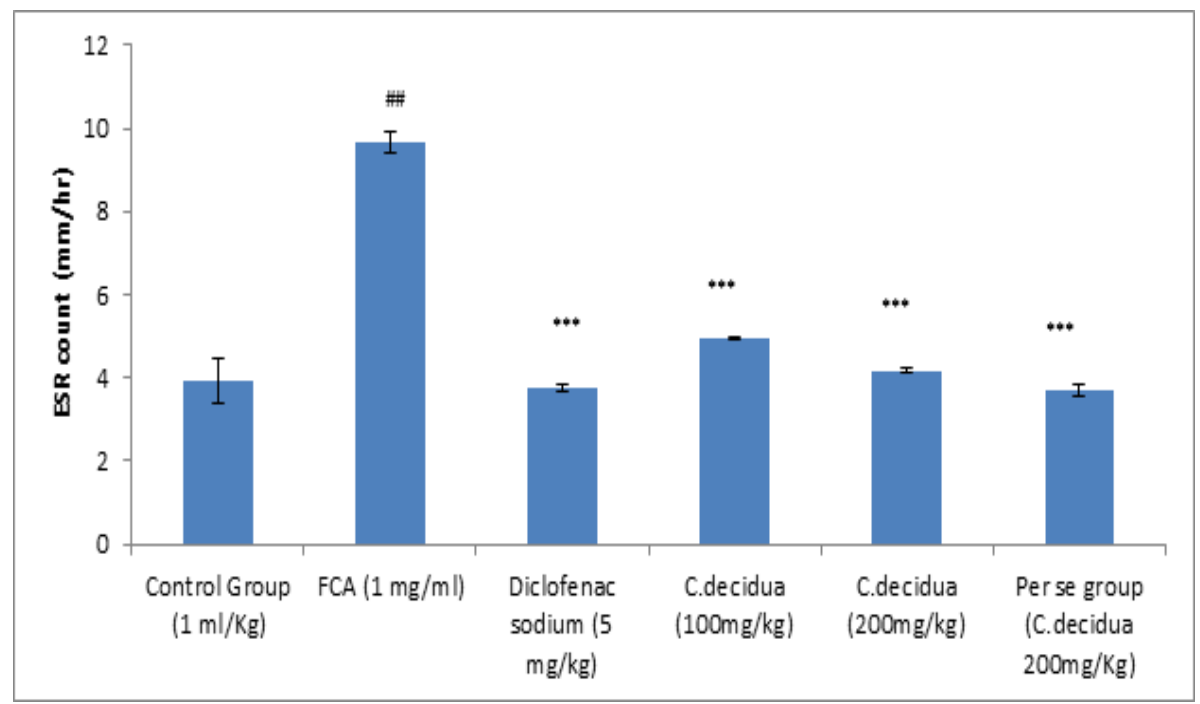

Figure 3. Effect of Capparis decidua on ESR count $\mathrm{mm} / \mathrm{hr}$ test in FCA-induced arthritic rats; Data are expressed as mean \pm S.E.M. $(\mathrm{n}=6)$. Data analyzed by one-way Analysis of Variance (ANOVA) followed by Dunnet's multiple tests for comparison. ${ }^{\# \#} \mathrm{P}<0.001$ as compared to control. ***P $<$ 0.001 as compared to FCA

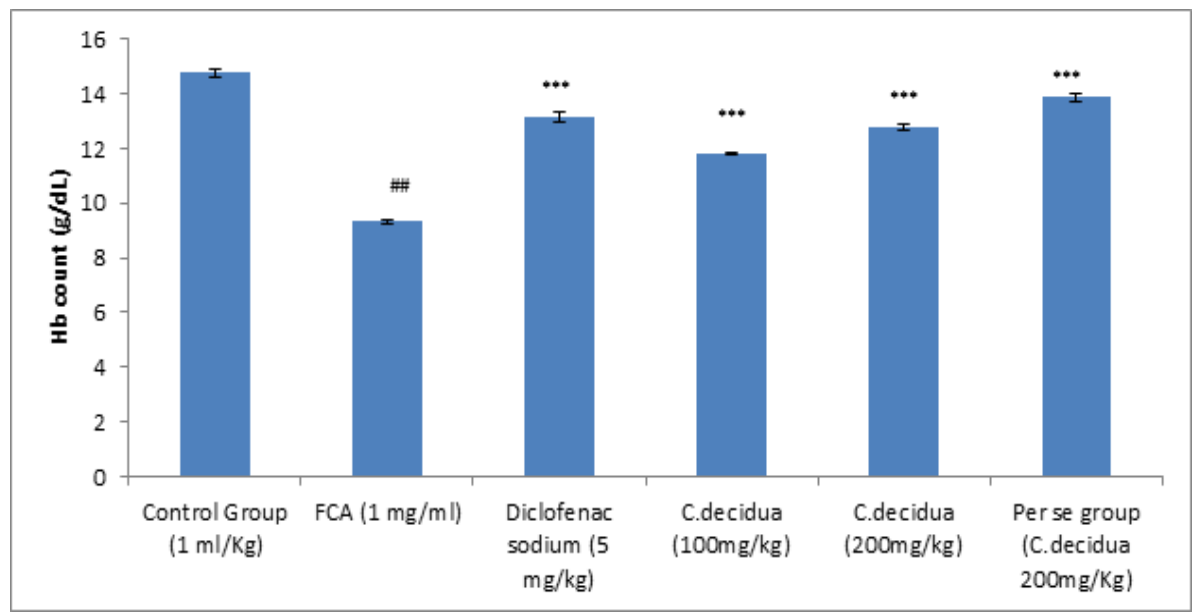

Figure 4. Effect of Capparis decidua on Hemoglobin count $\mathrm{g} / \mathrm{dL}$ count test in FCA-induced arthritic rats; Data are expressed as mean \pm S.E.M. $(\mathrm{n}=6$ ).

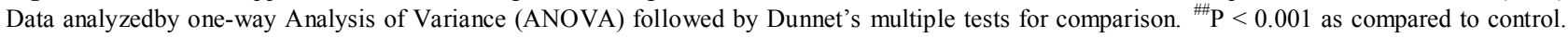
$* * * \mathrm{P}<0.001$ as compared to FCA.

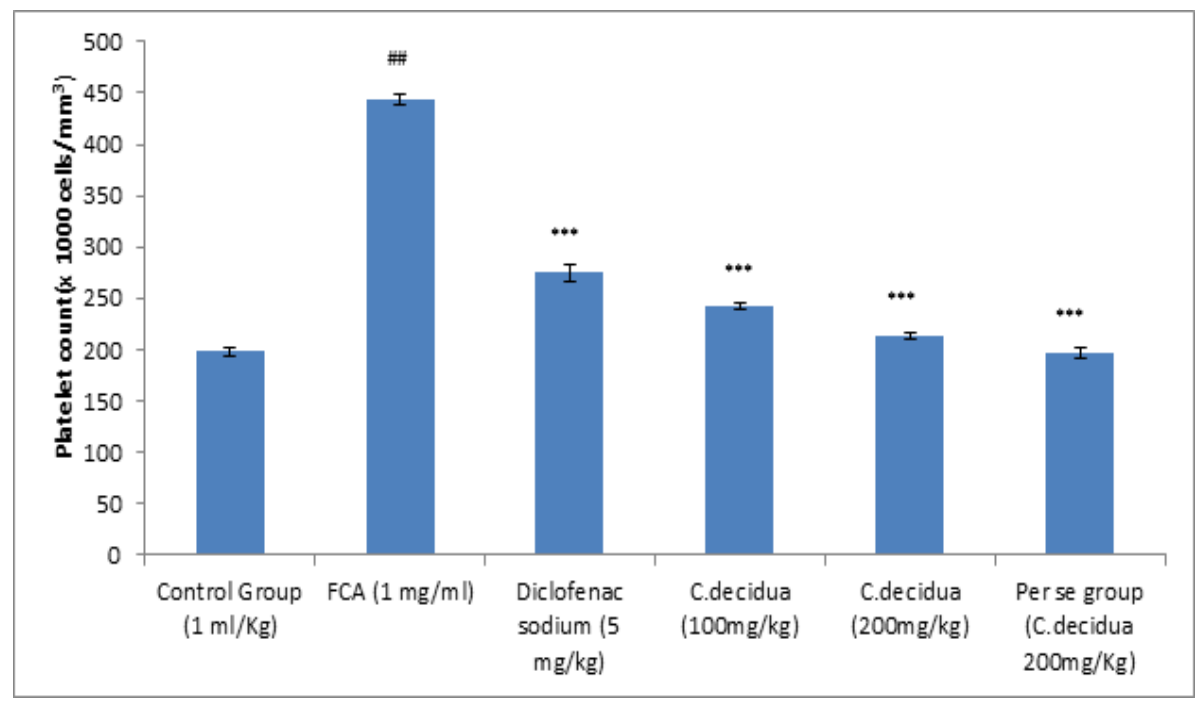

Figure 5. Effect of Capparis decidua on Platelet count $\left(x 1000\right.$ cells $\left./ \mathrm{mm}^{3}\right)$ test in FCA-induced arthritic rats; Data are expressed as mean \pm S.E.M. (n =6). Data analyzedby one-way Analysis of Variance (ANOVA) followed by Dunnet's multiple tests for comparison. ${ }^{\text {\#\# }}<0.001$ as compared to control. $* * * \mathrm{P}<0.001$ as compared to FCA. 


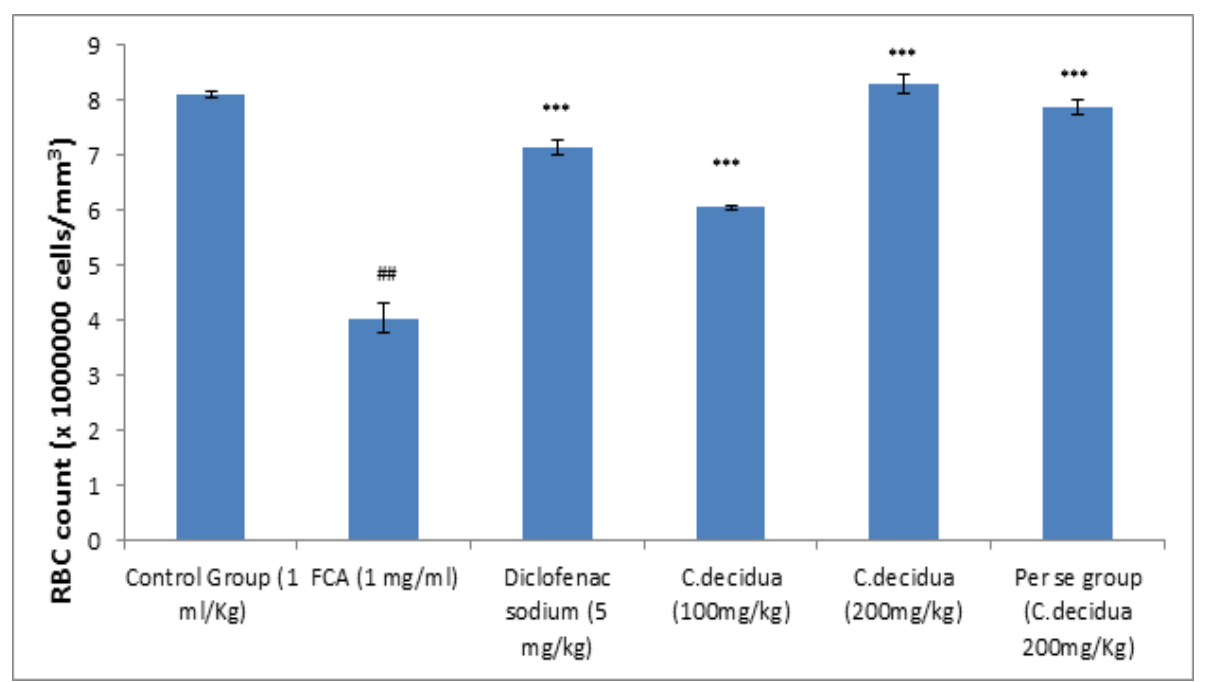

Figure 6. Effect of Capparis decidua on RBC count test in FCA-induced arthritic rats; Data are expressed as mean \pm S.E.M. $(n=6)$. Data analyzedby one-way Analysis of Variance (ANOVA) followed by Dunnet's multiple tests for comparison. ${ }^{\# /} \mathrm{P}<0.001$ as compared to control. ${ }^{* * *} \mathrm{P}<0.001$ as compared to FCA treated.

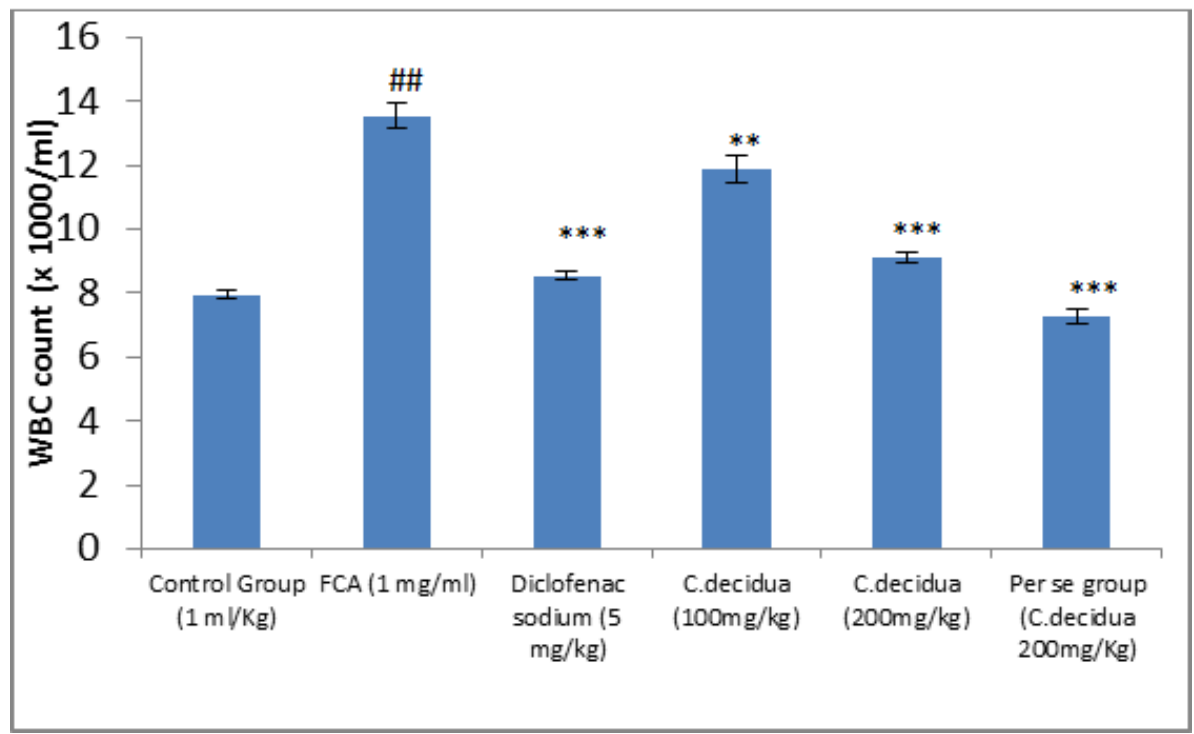

Figure 7. Effect of Capparis decidua on WBC count test in FCA-induced arthritic rats; Data are expressed as mean \pm S.E.M. $(n=6)$. Data analyzed by one-way Analysis of Variance (ANOVA) followed by Dunnet's multiple tests for comparison. ${ }^{\# \#} \mathrm{P}<0.001$ as compared to control. ${ }^{* * *} \mathrm{P}<0.001$ as compared to FCA.

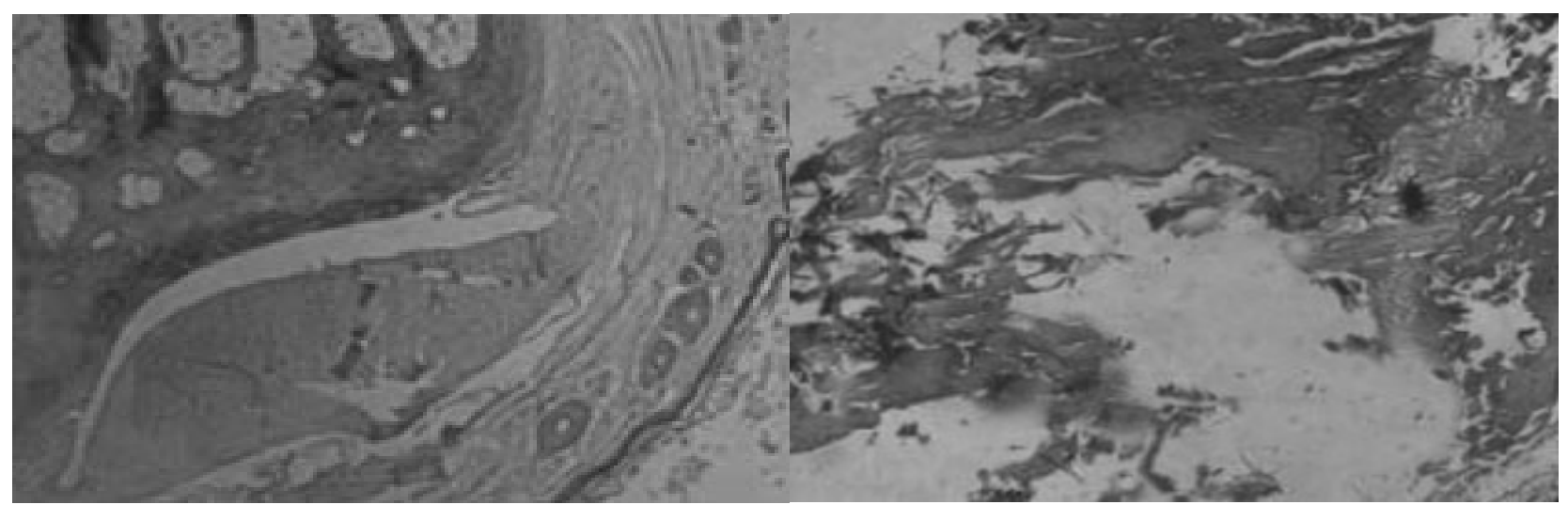




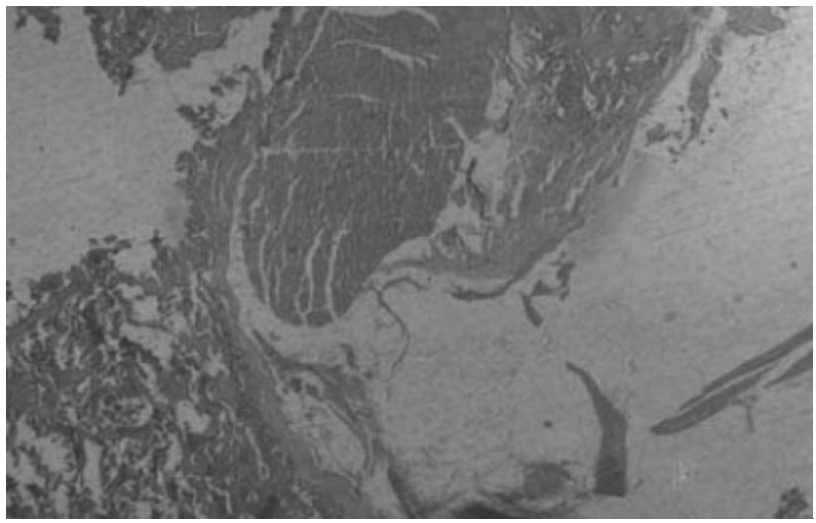

Figure 8.3

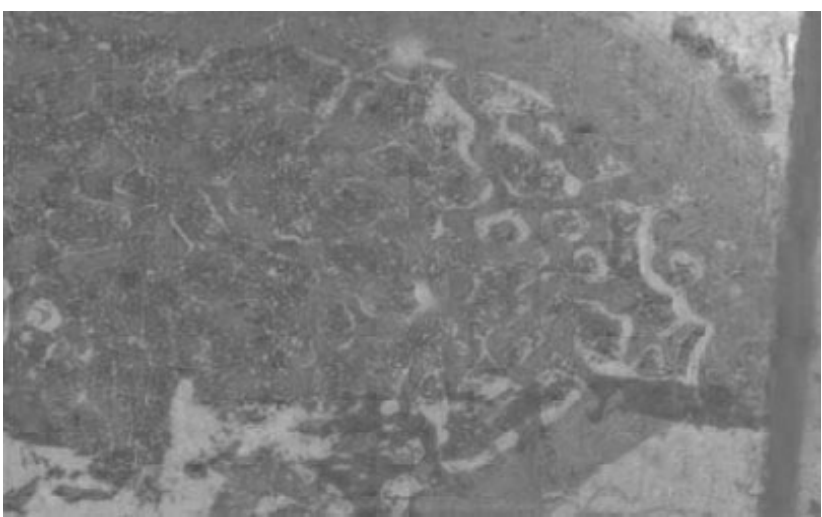

Figure 8.5

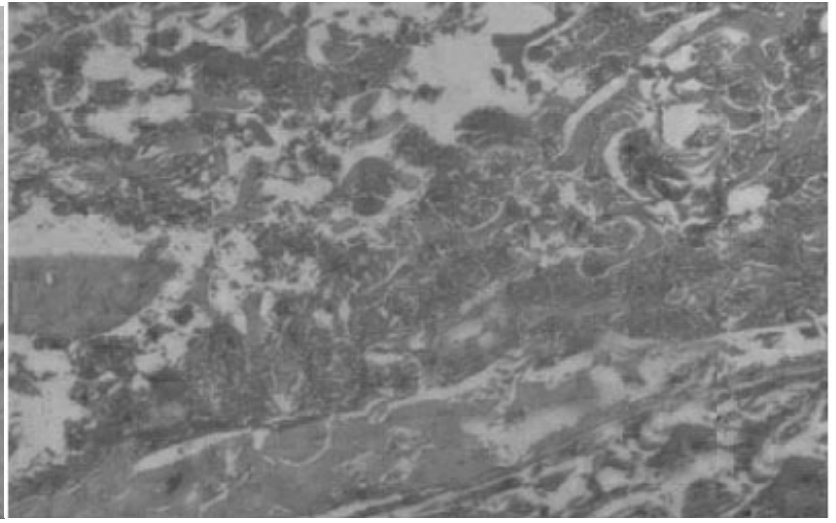

Figure 8.4

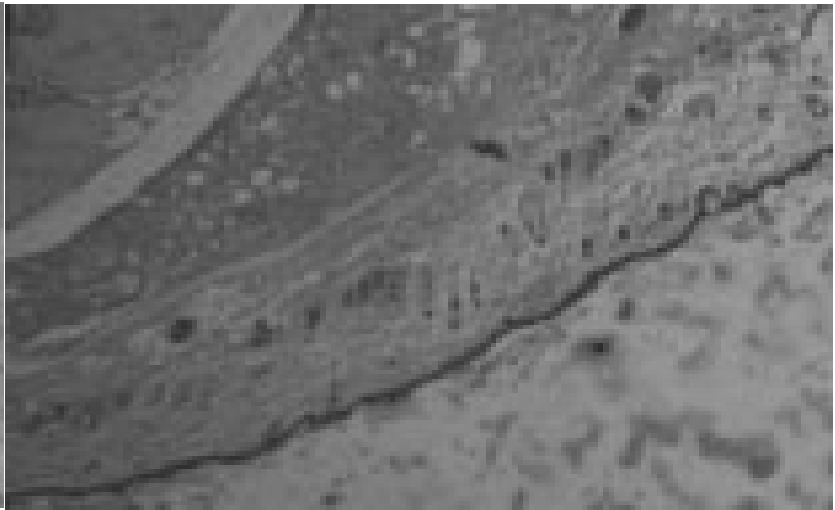

Figure 8.6

Figures 8.1-8.6. Effect of hydroalcoholic extract of $C$. decidua on histolopathology of ankle joint in experimental rats 8.1) Ankle joint synovial membrane structure in normal control rat; 8.2) Severe inflammation with synovial hyperplasia and increased vascularity, oedematous inflammation, inflammatory cell infiltrate of neutrophills in FCA induced arthritis rats; 8.3) Synovial membrane structure re-organising with decrease in oedema and inflammation in Diclofenac sodium rats; 8.4) Moderate healing in the synovial membrane in C. decidua extract $100 \mathrm{mg} / \mathrm{kg}$; 8.5 ) Decrease in inflammation with decrease in oedematous spaces, restructuring of synovial membrane with noticeable reduction of histological injury in $C$. decidua extract $200 \mathrm{mg} / \mathrm{kg}$; 8.6) Ankle joint synovial membrane structure in per se groups rats.

\section{Discussion}

Numerous restorative plants give alleviation of manifestations in rheumatoid joint inflammation whose impacts are tantamount to that of accessible regular therapeutic agents [26]. Acute toxicity study revealed the non-toxic nature of the extract at the dose of $4 \mathrm{~g} / \mathrm{kg}$. Limb swelling, proliferative synovitis, inflammatory cell infiltration and erosion of the bone and cartilage structure are clinical discoveries related to human arthritis and FCA-induced arthritis rat. Attributable to this likeness in pathologic highlights, the FCA-induced arthritis rat is a widely used model of rheumatoid arthritis in evaluating the efficacy of anti-inflammatory drugs [27]. In the present study, hydroalcoholic extract of $C$. decidua (100 and $200 \mathrm{mg} / \mathrm{kg}$ ) and per se treatment showed an anti-arthritic effect in the inflammatory parameter like paw volume. $C$. decidua extract significantly $(\mathrm{P}<0.001$ at $100 \& 200 \mathrm{mg} / \mathrm{kg})$ decreased the inflammation compared to the FCA treated the group as observed by decreased paw volume. The present study revealed that paw volume rises with ankle bone hardness in FCA treated rats. The body weight of
FCA treated group rats was prominently decreased compared with that of normal control rats. The results suggest that oral C. decidua extract $(100 \mathrm{mg} / \mathrm{kg}, 200 \mathrm{mg} / \mathrm{kg}$ and per se) reduced inflammatory body weight loss in arthritis induced rats. Thus, $C$. decidua gives protective action in terms of body weight. The decrease in body weight of FCA-induced arthritic rats in the present study is because ofdecreased intestinal absorption rate. Treatment with EACA significant inhibited weight loss in arthritic rats. Thus, EACA may have the potential as a therapeutic agent used for symptomatic treatment of rheumatoid arthritis because of its anti-inflammatory action which delays progression of disease [2]. Increase in the WBC count in FCA treated group rats indicates the leukocytosis in the joint region by infiltration of neutrophil cells. This data may be affirmed by the earlier study conducted by Glenn et al, 1965[28] who reported neutrophilia and leukocytosis on day 28 post-induction.

In arthritis decreased level of hemoglobin $(\mathrm{Hb})$ and red blood cells (RBCs) is caused because of the diminished reaction of the bone marrow erythropoietin and pulverization of untimely RBCs [29]. So also increment in 
the level of erythrocyte sedimentation rate (ESR) is credited to the quickened arrangement of endogenous proteins including plasma proteins, for example, fibrinogen, alpha and beta globulins. Henceforth these parameters are key biomarkers that are elevated during inflammation, stress and cell necrosis [30]. In our study, treatment with $C$. decidua extract in arthritic rats significantly increased the level of $\mathrm{RBC}$ and $\mathrm{Hb}$ while it decreased the level of ESR which can be credited to its mitigating potential. Ascend in a number of platelets in FCA treated group rats also indicated the inflammatory pathogenesis in the joint region while a decrease in the number of platelets in $\mathrm{C}$. decidua extract treated groups suggest the protective role of this plant in arthritis. In addition, the defensive impact of $C$. decidua in the progression of joint damage was additionally affirmed by the histopathological investigation of ankle joint. In the present study, ankle joint histopathological sections of normal control rats showed dense cellular infiltration, synovial hyperplasia alongside pannus formation. Treatment with $C$. decidua in arthritic rats showed reduced cellular infiltration, synovial hyperplasia and pannus formation in ankle joint, which suggests that $C$. decidua can effectively inhibit the disease progression in arthritic rats. Since our study has shown that hydroalcoholic extract of $C$. decidua possesses significant anti-arthritic activity in experimental animals. C. decidua showed the presence of numerous constituents like phenols, alkaloids, terpenoids, flavonoids, saponins, cardiac glycosides, steroids, tannins, and carbohydrates in the present study.

Earlier studies have shown the presence of chemical constituents like n-Triacontane, $\mathrm{n}$-Pentacosane, $\beta$-Carotene, Carbohydrates, Proteins, Glucosinolates, n-Triacontanol [31-32], Tetrahydropyran-2-one, 2-Carboxy-1-dimethylpyrrolidine 9 (33), Nonacosane (34), Quercitin, Isodulcite, Nonacosane, Thymol, Isopropyl isothiocyanate, Butyl isothiocyanate, 2-Hexenol (33), Phenylpropanoid, Terpenoids, Isothiocyanate, n-Alkalenes. Thomnocitrine, Kaempferol, Isorhamnetin, rhamnocitrin, rhamnetin, rhamnazin, quaternary ammonium compounds, Spermidine alkaloid (35), Isocodonocarpine, Capparine, Capparinine, Cappariline, Codonocarpine (36), Cadabacine-26-O- $\beta$-d-glucoside, Capparisine, Capparispine-26-O-d-glucoside, $\mathrm{N}$-acetylated spermidine, 14-N-acetyl isocodonocarpine, 15-N-acetylcapparisine, Rutin, $1-$ Stachydrine, $\quad \beta$-Sitosterol, Terpenoids, Capparisesterpenolide (37), Glucocapparin, Capric acid, Monoterpenes, Sesquiterpenes, Tocopherols (38).

It could be said that the antiarthritic activity could be attributed to these phytochemical.

\section{Conclusions}

The study revealed that hydroalcoholic extract of $C$. decidua $(100$ and $200 \mathrm{mg} / \mathrm{kg}$ ) possess anti-arthritic activity that is mediated by its suppression of swelling and inflammation of paw, reduction of a decrease in body weight, and analyzed by hematological, and histopathological parameters. All these results thus reflect that $C$. decidua provide a pharmacological rationale for the traditional use of the plant against rheumatoid arthritis. The possible compounds that participated in the treatment of arthritis could be attributed to phytochemicals found in the C. decidua plant.

\section{Acknowledgements}

We are very grateful to Prof. Kailash Agrawal \& Dr. Manju Sharma of Department of Botany, the University of Rajasthan for their appropriate and constructive suggestions as well as Dr. Ramji Gupta and Dr. Amit Singh of R.V. Northland Institute for their unduly support.

\section{Conflict of Interest}

Authors declare that there are no conflicts of interest.

\section{REFERENCES}

[1] G. V. Bihani, S. R. Rojatkar, and S. L. Bodhankar, "Anti-arthritic activity of methanol extract of Cyathocline purpurea (whole plant) in Freund's complete adjuvant-induced arthritis in rats," Biomed. Aging Pathol., 2014. http://dx.doi.org/10.1016/j.biomag.2014.04.007.

[2] D. D. Bandawane, S. Beautikumari, S. S. Gate, and A. N. Patel, "Evaluation of anti-arthritic activity of ethyl acetate fraction of Cassia auriculata Linn. leaves," Biomed. Aging Pathol., vol. 4, no. 2, pp. 105-115, 2014.

[3] P. Patel, D. Patel, and N. Patel, "Experimental investigation of anti-rheumatoid activity of Pleurotus sajorcaju in adjuvant-induced arthritic rats," Chin. J. Nat. Med., vol. 10, no. 4, pp. 269-274, 2012.

[4] P. D. Verma, R. D. Dangar, K. N. Shah, D. M. Gandhi, and B. N. Suhagia, "Pharmacognostical potential of Capparis decidua Edgew," J. Appl. Pharm. Sci., vol. 1, no. 10, pp. 611,2011

[5] N. Chahlia, "Effect of Capparis decidua on hypolipidemic activity in rats," J. Med. Plants Res., vol. 3, no. 6, pp. 481484, 2009.

[6] P. K. Dhakad, P. K. Sharma, and S. Kumar, "A Review on Ethnobiological \& Medicinal Potential of Capparaceae Family Plant: Capparis decidua ( Forssk .) Edgew," Adv. Pharmacol. Pharm., vol. 4, no. 3, pp. 27-39, 2016.

[7] M. Goyal, B. P. Nagori, and D. Sasmal, "Sedative and anticonvulsant effects of an alcoholic extract of Capparis decidua," J. Nat. Med., vol. 63, no. 4, pp. 375-379, 2009.

[8] Upadhyay RK, Rohatgi L, Chaubey MK, Jain SC. 
Ovipositional responses of the pulse beetle, Bruchuschinesis (Coleopetra Bruchidae) to extracts and compounds of Capparis decidua (Forssk.) Edgew. J Agr Food Chem. 2006; 54: 9747-9451.

[9] Martınez-Carballo E, Sitka A, Gonzalez-Barreiro C, Kreuzinger N, Furhacker M, Scharf, S. Determination of selected quaternary ammonium compounds by liquid chromatography with mass spectrometry. Part I. Application to surface, waste and indirect discharge water samples in Austria. Environ Poll. 2007; 145: 489-496.

[10] Gaind K, Juneja T, Bhandarkar P. Volatile principle from seeds of Capparis decidua (Forssk.) Edgew. Kinetics of in vitro antibacterial activity against Vibrio cholera ogava, inaba, and eltor. Indian J. Pharm. 1972; 34: 86-88.

[11] Tepe B, Sokmen M, Akpulat HA, Sokmen A. Screening of the antioxidant potentials of six Salvia species from Turkey. Food Chem. 2006; 95: 200-204.

[12] Ihme N, Kiesewetter H, Jung F, Hoffman K, Birk A, Müller A. Grützner, K., Leg oedema protection from a buckwheat herb tea in patients with chronic venous insufficiency: a single-centre, randomised, double-blind, placebo-controlled clinical trial. Eur. J. Clin. Pharmacol. 1996; 50: 443-447.

[13] Ahmad VU, Ismail N, Arif S, Amber AUR. Two new $\mathrm{N}$-acetylated spermidine alkaloids from Capparis decidua (Forssk.) Edgew. J. Nat. Prod. 55; 1992: 1509-1512.

[14] Yadav P, Sarkar S, Bhatnagar D. Lipid peroxidation and antioxidant enzymes in erythrocytes and tissues in aged diabetic rats. Indian J. Exp. Biol. 1997; 35: 389-392.

[15] Ali SA, Al-Amin TH, Mohamed AH, Gameel AA. Hepatoprotective activity of aqueous and methanolic extract of Capparis decidua stem against Carbon tetrachloride induced liver damage in rats. Journal of Pharmacology and Toxicology. 2009; 4 (4): 167-172.

[16] Zaman S, Akhtar N, Khan BA, Mahmood T, Rasul A, Mahmood A, Aamir MN, Ali A. Development of a sebum control cream from a local desert plant Capparis deciduas. Journal of Medicinal Plants Research. 2012; 6(5): 744-748.

[17] Purohit A, Vyas KB. Hypolipidaemic efficacy of Capparis decidua fruit and shoot extracts in cholesterol fed rabbits. Indian J Exp. Biol. 2005; 43(10): 863-866.

[18] Goyal R, Grewal R. The influence of teent (Capparis decidua (Forssk.) Edgew. on human plasma triglycerides, total lipids and phospholipids. Nutr. Health. 2003; 17: 7176.

[19] Upadhyay RK, Jaiswal G, Ahmad S, Khanna L, Jain SC. Antitermite activities of Capparis decidua Extracts and Pure Compounds against Indian White Termite Odonto termes obesus (Isoptera: Odontotermitidae). Hindawi Publishing Corporation Psyche Volume 2012, Article ID 820245, 9 pages doi: $10.1155 / 2012 / 820245$.

[20] Dev SK, Shukla A, Choudhury PK, Singh GK. Analgesic and anti-nociceptive activity of hydroethanolic extract of Capparis decidua (Forssk.) Edgew. Linn. Asian Journal of Pharmacy and Pharmacology. 2015; 1(1): 40-44.

[21] P. Patel, D. Patel, N. Patel, "Experimental investigation of anti-rheumatoid activity of Pleurotus sajor-caju in adjuvant-induced arthritic rats," Chin. J. Nat. Med. vol. 10, no. 4, pp. 269-74, 2012.

[22] D. Asquith, A. Miller, I. McInnes, F. Liew, "Animal models of rheumatoid arthritis," Eur J Immunol., vol.39, no.8, pp. 2040-2044, 2009.

[23] J. Lee, K. Kim, S. Jeong, S. Lee, H. Park, N. Kim, "Anti-inflammatory, anti-nociceptive, and anti-psychiatric effects by the rhizomes of Alpinia officinarumon complete Freund's adjuvant-induced arthritis in rats" $J$ Ethnopharmacol. vol. 126, pp. 258-64, 2009.

[24] A. Mehta, N. Sethiya, C. Mehta, G. Shah, "Anti-arthritis activity of roots of Hemidesmus indicus R. Br. (Anantmul) in rats," Asian Pac J Trop Med ,pp. 130-135, 2012.

[25] M. Patil, A. Kandhare, S. Bhise, "Anti-arthritic and anti-inflammatory activity of Xanthium strumarium L. ethanolic extract in Freund's complete adjuvant induced arthritis," Biomed Aging Pathol, vol. 2, pp. 6-15, 2012.

[26] R. Verpoorte, "Exploration of nature's chemodiversity: the role of secondary metabolites as leads in drug development," Drug Discov Today, vol. 3, pp. 232-238, 1999.

[27] M.Noguchi, A. Kimoto, S. Kobayashi, T. Yoshino, K. Miyata, M. Sasamata, "Effect of celecoxib, a cyclooxygenase-2 inhibitor, on the pathophysiology of adjuvant arthritis in rat," Eur J Pharmacol. Vol. 5, No. 13, pp. 229-235, 2005.

[28] E.M. Glenn, J. Gray, W. Kooyers, "Chemical changes in adjuvant-induced polyarthritis of rats," Am J Vet Res, vol. 26, pp. 1195-1203, 1965.

[29] C.R. Patil, A.D. Rambhade, R.B. Jadhav, K.R. Patil, V.K. Dubey, B.M. Sonara, "Modulation of arthritis in rats by Toxicodendron pubescens and its homeopathic dilutions," Homeopathy, vol. 100, pp. 131-137, 2011.

[30] M. Maria, M. Engeniusz, K. Miroslaw, K. Maria, P. Iwona, "Clinical findings and morphological and biochemical changes in blood and histological changes in internal organs," Rheumatology, vol. 21, pp. 213-245, 1983.

[31] Rathee S, Rathee P, Rathee D, Rathee D, Kumar V. Phytochemical and pharmacological potential of kair (Capparis decidua (Forssk.) Edgew.) Int. J. Phytomed. 2011; 2: $10-17$.

[32] Mishra S, Tomar P, Lakra N. Medicinal and food value of Capparis decidua (Forssk.) Edgew - a harsh terrain plant. Indian J. Trad. Knowl. 2007; 6: 23.

[33] Chahlia N. Effect of Capparis decidua (Forssk.) Edgew. on hypolipidemic activity in rats. J Med Plant Res 2009; 3: 481-4.

[34] Nadkarni KM, Nadkarni A. Indian Materia Medica: With Ayurvedic, Unani-tibbi, Siddha, Allopathic, Homeopathic Naturopathic \& Home Remedies, 3rd Ed. Popular Book Depot.

[35] Delaveau P, Koudogbom B, Pousset JL, Alcaloïdes chez les capparidaceae. Phytochemistry. 1973; 12: 2893-2895.

[36] McLean WFH, Blunden G, Jewers K. Quaternary ammonium compounds in the Capparaceae. Biochem Syst Ecol. 1996; 24: 427-434.

[37] Ahmad VU, Arif S, Amber AUR, Fizza K. Capparisinine, a 
new alkaloid from Capparis decidua (Forssk.) Edgew. Liebigs Ann. Chem. 1987; 161-162

[38] Arena A, Bisignano G, Pavone B, Tomaino A, Bonina F,
Saija A, Cristani MD, Arrigo M, Trombetta D. Antiviral and immunomodulatory effect of a lyophilized extract of Capparis spinosa L. buds. Phytother. Res. 2008; 22: 313317. 